PSTCHOMETRIKA-VOL. 22 , No. 4

DECEMBER, 1957

\title{
A MODEL FOR RESPONSE TENDENCY COMBINATION*
}

\author{
DAvid BIRCH \\ UNIVERSITY OF MICHIGAN
}

\begin{abstract}
A model is proposed to predict the performance on a compound stimulus as a function of the performance on the component stimuli in a two-choice situation. Data from a learning task are used to evaluate the model.
\end{abstract}

Any theory of behavior which analyzes a stimulus complex into components and attempts to account for responses to the complex on the basis of response tendencies to the components faces the problem of specifying the rule for the combination of the component response tendencies. Theorists such as Hull [4], Thurstone [8], Gulliksen [3], Spence [7], Estes and Burke [2], Bush and Mosteller [1], and Restle [5] have incorporated combination rules within their theories and then made use of them in deriving implications from their theories. Seldom, however, has the combination rule itself been the focus of attention for these theorists. One recent instance is a study by Schoeffler [6] who carried out a test of a combination rule derived from the Estes-Burke learning theory. The rule is linked directly to the parameters of the theory and certain assumptions about the parameters are made by Schoeffler in bringing the rule to test.

This paper presents the development of a model for combining response tendencies in a two-choice situation and reports a test for the fit of the model to data. The basis for the definition of the parameters of the model proposed, as well as the impetus for the development of the model, are derived from Hullian behavior theory. However, the combination rule, specified by the interrelationships of the parameters of the model, does not depend upon any particular learning theory and, therefore, may be of value in a variety of situations where problems of combination arise.

\section{A Model for Response Tendency Combination}

The difference in response tendency strength for stimulus $a, D_{a}=$ $\left({ }_{a} E_{s}-{ }_{a} E_{v}\right)$, at any given point in time will be considered to be in one of three states: $D_{a} \geq d, D_{a} \leq-d$, or $-d<D_{a}<d$, where $d$ is a parameter with a value such that $\operatorname{Pr}\left\{u \mid D_{a} \geq d\right\}=1, \operatorname{Pr}\left\{u \mid D_{a} \leq-d\right\}=0$, and $\operatorname{Pr}\left\{u \mid-d<D_{a}<d\right\}=.5$. Let $\operatorname{Pr}\left\{D_{a} \geq d\right\}, \operatorname{Pr}\left\{D_{a} \leq-d\right\}$, and $\operatorname{Pr}\{-d<$

*The initial work on the model was carried out under the Summer Faculty Research Fellowship Program of the Horace H. Rackham School of Graduate Studies at the University of Michigan. Acknowledgment is also due Mr. Richard Anderson for his assistance in data collection. 
$\left.D_{a}<d\right\}=1-\operatorname{Pr}\left\{D_{a} \geq d\right\}-\operatorname{Pr}\left\{D_{a} \leq-d\right\}$ be the probabilities that the difference in response tendency strengths is in each of the three states.

It then follows that the compound probability of obtaining $u$ and $v$ when $a$ is presented may be written as

(1) $\operatorname{Pr}\{u \mid a\}=\operatorname{Pr}\left\{D_{a} \geq d\right\}+(.5)\left[1-\operatorname{Pr}\left\{D_{a} \geq d\right\}-\operatorname{Pr}\left\{D_{a} \leq-d\right\}\right]$

and

(2) $\operatorname{Pr}\{v \mid a\}=\operatorname{Pr}\left\{D_{a} \leq-d\right\}+(.5)\left[1-\operatorname{Pr}\left\{D_{a} \geq d\right\}-\operatorname{Pr}\left\{D_{a} \leq-d\right\}\right]$.

A corresponding development for $b$ gives

(3) $\operatorname{Pr}\{u \mid b\}=\operatorname{Pr}\left\{D_{b} \geq d\right\}+(.5)\left[1-\operatorname{Pr}\left\{D_{b} \geq d\right\}-\operatorname{Pr}\left\{D_{b} \leq-d\right\}\right]$

and

(4) $\operatorname{Pr}\{v \mid b\}=\operatorname{Pr}\left\{D_{b} \leq-d\right\}+(.5)\left[1-\operatorname{Pr}\left\{D_{b} \geq d\right\}-\operatorname{Pr}\left\{D_{b} \leq-d\right\}\right]$.

Since $\operatorname{Pr}\{u \mid a\}+\operatorname{Pr}\{v \mid a\}=1$ and $\operatorname{Pr}\{u \mid b\}+\operatorname{Pr}\{v \mid b\}=1$, there are available two independent equations in the four unknowns, $\operatorname{Pr}\left\{D_{a} \geq d\right\}$, $\operatorname{Pr}\left\{D_{a} \leq-d\right\}, \operatorname{Pr}\left\{D_{b} \geq d\right\}$, and $\operatorname{Pr}\left\{D_{b} \leq-d\right\}$.

The compound stimulus $(a, b)$ is defined as the joint presentation of $a$ and $b$, and this compound stimulus can be characterized in four mutually exclusive and exhaustive ways by the responses obtained to $a$ and $b$ upon separate presentation of these stimuli. That is, $a$ and $b$ may both be responded to with $u, a$ may be responded to with $u$ and $b$ with $v, a$ may be responded to with $v$ and $b$ with $u$, or both $a$ and $b$ may be responded to with $v$. Let the corresponding designations of $(a, b)$ be $\left(a_{u}, b_{u}\right),\left(a_{u}, b_{v}\right),\left(a_{v}, b_{u}\right)$, and $\left(a_{v}, b_{v}\right)$.

If the total probability of $u$ to the presentation of $(a, b)$ is denoted $\operatorname{Pr}\{u \mid(a, b)\}$, then

$$
\begin{aligned}
\operatorname{Pr}\{u \mid(a, b)\}= & \operatorname{Pr}\left\{u \mid\left(a_{u}, b_{u}\right)\right\} \cdot \operatorname{Pr}\left\{a_{u}, b_{u}\right\}+\operatorname{Pr}\left\{u \mid\left(a_{u}, b_{v}\right)\right\} \\
& \cdot \operatorname{Pr}\left\{a_{u}, b_{v}\right\}+\operatorname{Pr}\left\{u \mid\left(a_{v}, b_{u}\right)\right\} \cdot \operatorname{Pr}\left\{a_{v}, b_{u}\right\} \\
+ & \operatorname{Pr}\left\{u \mid\left(a_{v}, b_{v}\right)\right\} \cdot \operatorname{Pr}\left\{a_{v}, b_{v}\right\},
\end{aligned}
$$

where the entries on the right-hand side of the equation are the independent contributions from the four classes of $(a, b)$. By writing each of these terms separately as a function of $\operatorname{Pr}\left\{D_{a} \geq d\right\}, \operatorname{Pr}\left\{D_{a} \leq-d\right\}, \operatorname{Pr}\left\{D_{b} \geq d\right\}$, and $\operatorname{Pr}\left\{D_{b} \leq-d\right\}$, a total of six experimentally independent equations in the four unknowns will be available so that the values of the unknowns are overdetermined.

It follows from (1), (2), (3), and (4) that the probabilities of occurrence of the four classes of $(a, b)$ are 
$\operatorname{Pr}\left\{a_{u}, b_{u}\right\}=\operatorname{Pr}\{u \mid a\} \cdot \operatorname{Pr}\{u \mid b\}=\operatorname{Pr}\left\{D_{a} \geq d\right\} \cdot \operatorname{Pr}\left\{D_{b} \geq d\right\}$

(6)

$+\operatorname{Pr}\left\{D_{a} \geq d\right\} \cdot(.5)\left[1-\operatorname{Pr}\left\{D_{b} \geq d\right\}-\operatorname{Pr}\left\{D_{b} \leq-d\right\}\right]$

$$
\begin{aligned}
& +(.5)\left[1-\operatorname{Pr}\left\{D_{a} \geq d\right\}-\operatorname{Pr}\left\{D_{a} \leq-d\right\}\right] \cdot \operatorname{Pr}\left\{D_{b} \geq d\right\} \\
& +(.5)\left[1-\operatorname{Pr}\left\{D_{a} \geq d\right\}-\operatorname{Pr}\left\{D_{a} \leq-d\right\}\right] \\
& +(.5)\left[1-\operatorname{Pr}\left\{D_{b} \geq d\right\}-\operatorname{Pr}\left\{D_{b} \leq-d\right\}\right] ;
\end{aligned}
$$

$\operatorname{Pr}\left\{a_{w}, b_{v}\right\}=\operatorname{Pr}\{u \mid a\} \cdot \operatorname{Pr}\{v \mid b\}=\operatorname{Pr}\left\{D_{a} \geq d\right\}$

$\cdot \operatorname{Pr}\left\{D_{b} \leq-d\right\}+\operatorname{Pr}\left\{D_{a} \geq d\right\} \cdot(.5)\left[1-\operatorname{Pr}\left\{D_{b} \geq d\right\}\right.$

(7)

$\left.-\operatorname{Pr}\left\{D_{b} \leq-d\right\}\right]+(.5)\left[1-\operatorname{Pr}\left\{D_{a} \geq d\right\}\right.$

$\left.-\operatorname{Pr}\left\{D_{a} \leq-d\right\}\right] \cdot \operatorname{Pr}\left\{D_{b} \leq-d\right\}$

$+(.5)\left[1-\operatorname{Pr}\left\{D_{a} \geq d\right\}-\operatorname{Pr}\left\{D_{a} \leq-d\right\}\right]$

$\cdot(.5)\left[1-\operatorname{Pr}\left\{\overline{D_{b}} \geq d\right\}-\operatorname{Pr}\left\{D_{b} \leq-d\right\}\right] ;$

$\operatorname{Pr}\left\{a_{v}, b_{u}\right\}=\operatorname{Pr}\{v \mid a\} \cdot \operatorname{Pr}\{u \mid b\}=\operatorname{Pr}\left\{D_{a} \leq-d\right\} \cdot \operatorname{Pr}\left\{D_{b} \geq d\right\}$

$+\operatorname{Pr}\left\{D_{a} \leq-d\right\} \cdot(.5)\left[1-\operatorname{Pr}\left\{D_{b} \geq d\right\}-\operatorname{Pr}\left\{D_{b} \leq-d\right\}\right]$

(8)

$$
\begin{aligned}
& +(.5)\left[1-\operatorname{Pr}\left\{D_{a} \geq d\right\}-\operatorname{Pr}\left\{D_{a} \leq-d\right\}\right] \cdot \operatorname{Pr}\left\{D_{b} \geq d\right\} \\
& +(.5)\left[1-\operatorname{Pr}\left\{D_{a} \geq d\right\}-\operatorname{Pr}\left\{D_{a} \leq-d\right\}\right] \\
& +(.5)\left[1-\operatorname{Pr}\left\{D_{b} \geq d\right\}-\operatorname{Pr}\left\{D_{b} \leq-d\right\}\right]
\end{aligned}
$$

and

$$
\begin{aligned}
\operatorname{Pr}\left\{a_{a}, b_{v}\right\} & =\operatorname{Pr}\{v \mid a\} \cdot \operatorname{Pr}\{v \mid b\}=\operatorname{Pr}\left\{D_{a} \leq-d\right\} \cdot \operatorname{Pr}\left\{D_{b} \leq-d\right\} \\
+ & \operatorname{Pr}\left\{D_{a} \leq-d\right\} \cdot(.5)\left[1-\operatorname{Pr}\left\{D_{b} \geq d\right\}-\operatorname{Pr}\left\{D_{b} \leq-d\right\}\right] \\
+ & (.5)\left[1-\operatorname{Pr}\left\{D_{a} \geq d\right\}-\operatorname{Pr}\left\{D_{a} \leq-d\right\}\right] \cdot \operatorname{Pr}\left\{D_{b} \leq-d\right\} \\
+ & (.5)\left[1-\operatorname{Pr}\left\{D_{a} \geq d\right\}-\operatorname{Pr}\left\{D_{a} \leq-d\right\}\right] \\
& \cdot(.5)\left[1-\operatorname{Pr}\left\{D_{b} \geq d\right\}-\operatorname{Pr}\left\{D_{b} \leq-d\right\}\right] .
\end{aligned}
$$

The probability of $u$ for each of the classes may be obtained by weighting each component of $\operatorname{Pr}\left\{a_{u}, b_{u}\right\}, \operatorname{Pr}\left\{a_{u}, b_{v}\right\}, \operatorname{Pr}\left\{a_{v}, b_{u}\right\}$, and $\operatorname{Pr}\left\{a_{v}, b_{v}\right\}$ by an appropriate conditional probability of occurrence of $u$. The weights assumed are as follows: the conditional probability of $u$ is 1 , given that the combinations of response tendency states for $a$ and $b$ are $D_{a} \geq d$ and $D_{b} \geq d$, or $D_{a} \geq d$ and $-d<D_{b}<d$, or $-d<D_{a}<d$ and $D_{b} \geq d$; the conditional probability of $u$ is 0 given $D_{a} \leq-d$ and $D_{b} \leq-d$, or $D_{a} \leq-d$ and $-d<$ $D_{b}<d$, or $-d<D_{a}<d$ and $D_{b} \leq-d$; and the conditional probability of $u$ is .5 given $D_{a} \geq d$ and $D_{b} \leq-d$, or $D_{a} \leq-d$ and $D_{b} \geq d$, or $-d<$ 
TABLE 1

\begin{tabular}{|c|c|c|c|}
\hline \multirow{2}{*}{$\begin{array}{l}\text { Response } \\
\text { Tendency } \\
\text { States for a }\end{array}$} & \multicolumn{3}{|c|}{ Response Tendency States for $b$} \\
\hline & $\left(D_{b} \geqslant a\right)$ & $\left(-\mathrm{a}<D_{\mathrm{b}}<a\right)$ & $\left(D_{b} \leqslant-d\right)$ \\
\hline$\left(D_{a} \geqslant a\right)$ & 1 & 1 & .5 \\
\hline$\left(-\mathrm{d}<\mathrm{D}_{\mathrm{a}}<\mathrm{d}\right)$ & 1 & .5 & 0 \\
\hline$\left(D_{a} \leq-d\right)$ & .5 & 0 & 0 \\
\hline
\end{tabular}

$D_{a}<d$ and $-d<D_{b}<d$. These assumed values are presented in Table 1 . These weights in conjunction with (6), (7), (8), and (9) produce four equations in the four unknowns $\operatorname{Pr}\left\{D_{a} \geq d\right\}, \operatorname{Pr}\left\{D_{a} \leq-d\right\}, \operatorname{Pr}\left\{D_{b} \geq d\right\}$, and $\operatorname{Pr}\left\{D_{b} \leq-d\right\}$. Since the model under development was instigated by the problem of the prediction of performance to a compound stimulus as a function of the performance to the component stimuli, the relationships of (1), (2), (3), and (4) may be used to reduce (6), (7), (8), and (9) to functions of the two unknowns $\operatorname{Pr}\left\{D_{a} \geq d\right\}$ and $\operatorname{Pr}\left\{D_{b} \geq d\right\}$. The resulting, simplified equations are

$$
\begin{aligned}
& \operatorname{Pr}\left\{u \mid\left(a_{u}, b_{u}\right)\right\} \cdot \operatorname{Pr}\left\{a_{u}, b_{u}\right\}=(.5)\left[\operatorname{Pr}\left\{D_{a} \geq d\right\} \cdot \operatorname{Pr}\{u \mid b\}\right. \\
& +\operatorname{Pr}\left\{D_{b} \geq d\right\} \cdot \operatorname{Pr}\{u \mid a\}-\operatorname{Pr}\left\{D_{a} \geq d\right\} \cdot \operatorname{Pr}\left\{D_{b} \geq d\right\} \\
& +\operatorname{Pr}\{u \mid a\} \cdot \operatorname{Pr}\{u \mid b\}] \text {; } \\
& \operatorname{Pr}\left\{u \mid\left(a_{u}, b_{v}\right)\right\} \cdot \operatorname{Pr}\left\{a_{w}, b_{v}\right\}=(.5)\left[\operatorname{Pr}\left\{D_{a} \geq d\right\} \cdot \operatorname{Pr}\{v \mid b\}\right. \\
& \left.-\operatorname{Pr}\left\{D_{b} \geq d\right\} \cdot \operatorname{Pr}\{u \mid a\}+\operatorname{Pr}\{u \mid a\} \cdot \operatorname{Pr}\{u \mid b\}\right\} \\
& \operatorname{Pr}\left\{u \mid\left(a_{w}, b_{u}\right)\right\} \cdot \operatorname{Pr}\left\{a_{v}, b_{u}\right\}=(.5)\left[\operatorname{Pr}\left\{D_{b} \geq d\right\} \cdot \operatorname{Pr}\{v \mid a\}\right. \\
& \left.-\operatorname{Pr}\left\{D_{a} \geq d\right\} \cdot \operatorname{Pr}\{u \mid b\}+\operatorname{Pr}\{u \mid a\} \cdot \operatorname{Pr}\{u \mid b\}\right]
\end{aligned}
$$

and

$$
\begin{aligned}
\operatorname{Pr}\left\{u \mid\left(a_{v}, b_{v}\right)\right\} & \cdot \operatorname{Pr}\left\{a_{v}, b_{v}\right\}=(.5)\left[-\operatorname{Pr}\left\{D_{a} \geq d\right\}\right. \\
\cdot & \cdot \operatorname{Pr}\{u \mid b\}-\operatorname{Pr}\left\{D_{b} \geq d\right\} \cdot \operatorname{Pr}\{u \mid a\}+\operatorname{Pr}\left\{D_{a} \geq d\right\} \\
\cdot & \left.\operatorname{Pr}\left\{D_{b} \geq d\right\}+\operatorname{Pr}\{u \mid a\} \cdot \operatorname{Pr}\{u \mid b\}\right] .
\end{aligned}
$$

Finally, (5) becomes:

$$
\begin{aligned}
\operatorname{Pr}\{u \mid(a, b)\} & =\operatorname{Pr}\left\{D_{a} \geq d\right\}[(.5)-\operatorname{Pr}\{u \mid b\}] \\
+ & \operatorname{Pr}\left\{D_{b} \geq d\right\}[(.5)-\operatorname{Pr}\{u \mid a\}]+2 \operatorname{Pr}\{u \mid a\} \cdot \operatorname{Pr}\{u \mid b\} .
\end{aligned}
$$


It may also be noted from (10) and (13) that

$2 \operatorname{Pr}\left\{u \mid\left(a_{u}, b_{u}\right)\right\} \cdot \operatorname{Pr}\left\{a_{u}, b_{u}\right\}-\operatorname{Pr}\{u \mid a\} \cdot \operatorname{Pr}\{u \mid b\}$

$$
\begin{aligned}
& =\operatorname{Pr}\left\{D_{a} \geq d\right\} \cdot \operatorname{Pr}\{u \mid b\}+\operatorname{Pr}\left\{D_{b} \geq d\right\} \cdot \operatorname{Pr}\{u \mid a\} \\
& -\operatorname{Pr}\left\{D_{a} \geq d\right\} \cdot \operatorname{Pr}\left\{D_{b} \geq d\right\}=\operatorname{Pr}\{u \mid a\} \cdot \operatorname{Pr}\{u \mid b\} \\
& -2 \operatorname{Pr}\left\{u \mid\left(a_{v}, b_{v}\right)\right\} \cdot \operatorname{Pr}\left\{a_{\mathrm{r}}, b_{v}\right\},
\end{aligned}
$$

which indicates that it is necessary that

$$
\begin{aligned}
\operatorname{Pr}\{u \mid a\} \cdot \operatorname{Pr}\{u \mid b\}-\operatorname{Pr}\left\{u \mid\left(a_{u}, b_{u}\right)\right\} \\
\cdot \operatorname{Pr}\left\{a_{u}, b_{u}\right\}=\operatorname{Pr}\left\{u \mid\left(a_{v}, b_{v}\right)\right\} \cdot \operatorname{Pr}\left\{a_{v}, b_{v}\right\}
\end{aligned}
$$

if these two equations are to be consistent. The latter relationship provides a partial test of the model since all four of the values are experimentally independent observables. If this relationship can be shown to hold within reasonable limits, then (10) and (13) may be combined into

$$
\begin{aligned}
\operatorname{Pr}\left\{u \mid\left(a_{u}, b_{u}\right)\right\} & \cdot \operatorname{Pr}\left\{a_{u}, b_{u}\right\}-\operatorname{Pr}\left\{u \mid\left(a_{v}, b_{v}\right)\right\} \\
\cdot & \operatorname{Pr}\left\{a_{v}, b_{v}\right\}=\operatorname{Pr}\left\{D_{a} \geq d\right\} \cdot \operatorname{Pr}\{u \mid b\}+\operatorname{Pr}\left\{D_{b} \geq d\right\} \\
\cdot & \operatorname{Pr}\{u \mid a\}-\operatorname{Pr}\left\{D_{a} \geq d\right\} \cdot \operatorname{Pr}\left\{D_{b} \geq d\right\} .
\end{aligned}
$$

\section{A Test of the Model}

To obtain data for a test of the model, a learning task was carried out in which subjects were required to associate the response $D a c$ to each of ten letter pairs and ten number pairs, and the response $J i x$ to each of another set of ten letter pairs and ten number pairs. In dealing with the resulting data, it is convenient to define $u$ as a correct response, $C$, and $v$ as an incorrect response, $I$. Also, stimulus $a$ is defined as the set of twenty letter pairs, $L$, and stimulus $b$ as the set of twenty number pairs, $N$.

In constructing the letter pairs a total of ten letters $(B, F, G, H, K, N$, $\mathrm{Q}, \mathrm{S}, \mathrm{Y}$, and $\mathrm{Z}$ ) were used, and these were paired in such a fashion that each letter appeared in the first position twice, once to be associated with Dac and once with $J i x$, and in the second position twice, again once to be associated with $D a c$ and once with $J i x$. No two letters were ever paired more than once. The ten digits ( 0 through 9$)$ were treated in similar manner.

The subjects, 145 male volunteers from the introductory psychology class, participated in groups of approximately 14. To provide an opportunity for learning, the letter pairs and number pairs were shown individually in a random sequence on flash cards for 10 seconds, with the correct response exposed during the last 6 seconds. Subjects recorded no responses during the learning series but did record their responses during the test series, which was alternated with the learning series. 
Three learning and three test series were given. In the test series each of the 20 letter pairs, the 20 number pairs, and 20 compounds were presented individually in random order. Each compound was made up of a letter pair and a number pair chosen at random without replacement under the restriction that the same response be correct for both the letter pair and the number pair. Each test series employed a different pairing of the letters and numbers in the compounds so that the same compound never appeared more than once. Exposure time for each stimulus in the test series was five seconds, during which time the response was written.

Five experimental groups are distinguished on the basis of the relative amount of training offered on letters and numbers. For Group I of 30 subjects, two exposures of each letter pair and each number pair were provided in each learning series ( $L: N=2: 2)$; for Group II of 28 subjects $(L: N=2: 1)$; for Group III of 33 subjects ( $L: N=1: 2)$; for Group IV of 26 subjects $(L: N=3: 1)$ and for Group $V$ of 28 subjects $(L: N=1: 3)$.

The measure of the probability of correct response to the letters, the numbers, and the four classes of the compound is obtained for each of the 15 test series by pooling over stimuli and subjects. Table 2 contains these data.

TABLE 2

Obtained Probability of Correct Response for Ietters Alone, Numbers Alone and the Four Classes of the Letter-Number Compounds

\begin{tabular}{|c|c|c|c|c|c|c|c|c|c|c|c|c|c|c|c|}
\hline \multirow{2}{*}{$\begin{array}{l}\text { aroup } \\
\text { Test }\end{array}$} & \multicolumn{3}{|c|}{$(L: N=2: 2)$} & \multicolumn{3}{|c|}{$(L: N=2: 1)$} & \multicolumn{3}{|c|}{$(\tau: N=1: 2)$} & \multicolumn{3}{|c|}{$(L: N=3: 1)$} & \multicolumn{3}{|c|}{$(L: N=1: 3)$} \\
\hline & 1 & 2 & 3 & 1 & 2 & 3 & 1 & 2 & 3 & 1 & 2 & 3 & 1 & 2 & 3 \\
\hline${ }^{\mathrm{P}}\{c \mid I\}$ & .59 & .67 & .74 & .57 & .62 & .62 & .55 & .63 & .67 & .66 & .76 & .80 & .51 & .59 & .62 \\
\hline${ }^{\mathrm{P}}\{\mathrm{c|N}\}$ & .56 & .73 & .78 & .53 & .62 & .64 & .56 & .73 & .74 & .56 & .63 & .70 & .59 & .68 & .82 \\
\hline $\operatorname{Pr}\left\{c \mid\left(L_{C}, N_{C}\right)\right\}, F r\left\{L_{C}, N_{C}\right\}$ & .25 & .46 & .57 & .24 & .33 & .33 & .22 & .41 & .48 & .30 & .44 & .55 & 1.22 & .38 & .48 \\
\hline $\operatorname{Pr}\left\{c \mid\left(L_{c}, N_{I}\right)\right\} \operatorname{Pr}\left\{L_{c}, N_{I}\right\}$ & .13 & .10 & .10 & .12 & .12 & .14 & .11 & .09 & .07 & .23 & .20 & .17 & .11 & .03 & .05 \\
\hline $\operatorname{Pr}\left\{c \mid\left(L_{I}, N_{c}\right)\right\}+\operatorname{Pr}\left\{L_{I}, N_{d}\right\}$ & .13 & .17 & .15 & .13 & .12 & .14 & .18 & .20 & .17 & .09 & .07 & .09 & 1.22 & .23 & .25 \\
\hline $\operatorname{Pr}\left\{c \mid\left(I_{I}, N_{I}\right)\right\} \quad \operatorname{Pr}\left\{L_{I}, N_{I}\right\}$ & .08 & .02 & .02 & .11 & .07 & .06 & .08 & .04 & .04 & .04 & .05 & .02 & .09 & .04 & .02 \\
\hline $\operatorname{Pr}\{C \Gamma(I, N\}$ & .59 & .75 & .84 & .60 & .64 & .67 & .59 & .74 & .76 & .66 & .76 & .83 & .64 & .68 & .80 \\
\hline
\end{tabular}

A first test of the model comes from the relationship $\operatorname{Pr}\{C \mid L\} \cdot \operatorname{Pr}\{C \mid N\}$ $-\operatorname{Pr}\left\{C \mid\left(L_{C}, N_{C}\right)\right\} \cdot \operatorname{Pr}\left\{L_{C}, N_{C}\right\}=\operatorname{Pr}\left\{C \mid\left(L_{I}, N_{I}\right)\right\} \cdot \operatorname{Pr}\left\{L_{I}, N_{I}\right\}$ derived from (10) and (13). The differences between the values for the left side and the right side of the equations for the 15 observations have a mean of -.004 , a range of -.03 to .05 , and a root mean square deviation around 0 of .02 . It would appear that the fit is sufficiently good so that (11), (12), and (15) may be used in a further test of the model. 
TABLE 3

Derived values for $\operatorname{Pr}\left\{D_{L} \geqslant a\right\}$ and $\operatorname{Pr}\left\{D_{N} \geqslant d\right\}$ and predicted Probability of Correct fiesponse for the Four classes of the Lettermmber cornoounds

\begin{tabular}{|c|c|c|c|c|c|c|c|c|c|c|c|c|c|c|c|}
\hline & \multicolumn{3}{|c|}{$\left(2: n^{I}=2: 2\right\rangle$} & \multicolumn{3}{|c|}{$L: N=2: I$} & \multicolumn{3}{|c|}{$(x: N=1: 2\}$} & \multicolumn{3}{|c|}{$(L: N=3: 1)$} & \multicolumn{3}{|c|}{$(L ; N=1: 3)$} \\
\hline Tes & 1 & 2 & 3 & 1 & 2 & 3 & 1 & 2 & 3 & 1 & 2 & 3 & 1 & 2 & 3 \\
\hline $\operatorname{Fr}\{$ & .27 & .43 & .55 & .25 & .37 & .33 & .08 & .30 & .40 & .42 & .58 & .67 & -.09 & .19 & .28 \\
\hline & .27 & .57 & .65 & .27 & .37 & .31 & .22 & .53 & .62 & .13 & .30 & .52 & .13 & .62 & .69 \\
\hline $\operatorname{Pr}\left\{c \mid\left(L_{C}, N_{c}\right)\right\}$ & .28 & .47 & .56 & .26 & .35 & .35 & .23 & .42 & .48 & .32 & .45 & .55 & .16 & .39 & .49 \\
\hline $\operatorname{Pr}\left\{\mathrm{C}\left(\mathrm{L}_{\mathrm{C}}, \mathrm{N}_{\mathrm{I}}\right)\right.$ & .24 & .11 & .11 & .13 & .15 & .16 & .11 & .10 & .09 & .23 & .23 & .17 & .10 & .05 & .07 \\
\hline $\operatorname{Pr}\left\{C \mid\left(L_{T}, N_{C}\right)\right\}$ & .24 & .18 & .16 & .24 & .15 & .15 & .18 & .22 & .20 & .09 & .09 & .10 & .21 & .26 & .27 \\
\hline $\operatorname{Pr}\left\{c \mid\left\{L_{I}, N_{I}\right\}, \operatorname{Pr}\left\{L_{I}, N_{I}\right\}\right.$ & .05 & .02 & .10 & .04 & .03 & .05 & .08 & .03 & .02 & .05 & .03 & .01 & .24 & .01 & .02 \\
\hline $\operatorname{Pr}\{\mathrm{c} \mid \mathrm{z}, \mathrm{n}\}$ & .61 & .78 & .84 & .57 & .68 & .71 & .60 & .77 & .79 & .69 & .80 & .83 & .61 & .71 & .85 \\
\hline
\end{tabular}

With three equations, the two unknowns are overdetermined, and since there is no a priori reason for selecting any particular pair of equations for solution, it was decided to obtain all three solutions and use the means as the best estimates of $\operatorname{Pr}\left\{D_{L} \geq d\right\}$ and $\operatorname{Pr}\left\{D_{N} \geq d\right\}$. Accordingly, the appropriate empirical values for each of the three tests for each of the five groups were substituted into the equations and solutions for $\operatorname{Pr}\left\{D_{L} \geq d\right\}$ and $\operatorname{Pr}\left\{D_{N} \geq d\right\}$ obtained. The resulting mean values are shown in Table 3 . To obtain an indication of the consistency of the three equations, the standard deviation of the three estimates of $\operatorname{Pr}\left\{D_{L} \geq d\right\}$ and $\operatorname{Pr}\left\{D_{N} \geq d\right\}$ for each of the 15 determinations was computed. These values ranged from .01 to .19 and yielded a mean and median of .09 and .09 , respectively, for $\operatorname{Pr}\left\{D_{L} \geq d\right\}$. The range for $\operatorname{Pr}\left\{D_{N} \geq d\right\}$ was .01 to .19 with a mean and median of .10 and .12 , respectively.

The predicted values for $\operatorname{Pr}\left\{C \mid\left(L_{C}, N_{C}\right)\right\} \cdot \operatorname{Pr}\left\{L_{C}, N_{C}\right\}, \operatorname{Pr}\left\{C \mid\left(L_{C}, N_{I}\right)\right\}$. $\operatorname{Pr}\left\{L_{G}, N_{I}\right\}, \operatorname{Pr}\left\{C \mid\left(L_{I}, N_{C}\right)\right\} \cdot \operatorname{Pr}\left\{L_{I}, N_{C}\right\}, \operatorname{Pr}\left\{C \mid\left(L_{I}, N_{I}\right)\right\} \cdot \operatorname{Pr}\left\{L_{I}, N_{I}\right\}$, and $\operatorname{Pr}\{C \mid L, I\}$ using mean $\operatorname{Pr}\left\{D_{L} \geq d\right\}$ and mean $\operatorname{Pr}\left\{D_{N} \geq d\right\}$ are contained in Table 3. A comparison of the obtained values of Table 2 with the predicted values of Table 3 shows a quite satisfactory fit except for a small consistent tendency for the predicted values of $\operatorname{Pr}\left\{C \mid\left(L_{C}, N_{C}\right)\right\}$. $\operatorname{Pr}\left\{L_{C}, N_{C}\right\}, \operatorname{Pr}\left\{C \mid\left(L_{C}, N_{I}\right)\right\} \cdot \operatorname{Pr}\left\{L_{C}, N_{I}\right\}$, and $\operatorname{Pr}\left\{C \mid\left(L_{I}, N_{C}\right)\right\} \cdot$ $\operatorname{Pr}\left\{L_{I}, N_{C}\right\}$ to be too high and the predicted values of $\operatorname{Pr}\left\{C \mid\left(L_{I}, N_{I}\right)\right\}$. $\operatorname{Pr}\left\{L_{I}, N_{I}\right\}$ to be too low. This discrepancy is reflected in mean differences of $.007, .012, .013$, and -.013 between predicted and obtained values for these classes of the compound stimuli. The root mean square deviations of the 
differences around 0 for the same four classes of the compound stimuli and for the total, $\operatorname{Pr}\{C \mid L, N\}$, yielded values of $.021, .016, .018, .028$, and .031, indicating further the adequacy of the fit of the model to these data.

\section{REFERENCES}

[1] Bush, R. R. and Mosteller, F. A mathematical model for simple learning. Psychol. Rev., 1951, 58, 313-323.

[2] Estes, W. K. and Burke, C. J. A theory of stimulus variability in learning. Psychol. Rev., 1953, 60, 276-286.

[3] Gulliksen, H. A generalization of Thurstone's learning function. Psychometrika, 1953, 18, 297-307.

[4] Hull, C. L. Principles of behavior. New York: Appleton-Century-Crofts, 1943.

[5] Restle, F. A theory of discrimination learning. Psychol. Rev., 1955, 62, 11-19.

[6] Schoeffler, M. O. Probability of response to compounds of discriminated stimuli. J. exp. Psychol., 1954, 48, 323-329.

[7] Spence, K. W. The nature of discrimination learning in animals. Psychol. Rev., 1936, $43,427-449$.

[8] Thurstone, L. L. The learning function. J. gen. Psychol, 1930, 3, 469-493.

Manuscript received $12 / 10 / 56$

Revised manuscript received $2 / 20 / 57$ 